\title{
Endometrial Carcinoma in a 20 Years Old or Less Female: A Rare Presentation of Four Cases
}

\section{Galina Chakalova*}

Department of Gynecological Oncology, National Oncological Center, Sofia, Bulgaria

\begin{abstract}
Endometrial cancer is the most common gynecological cancer and is a disease of postmenopausal women The disease appears in 20 years or less extremely rare. Four case of endometrial cancer in 20 years old or less female, treated at Department of Gynecological Oncology, National Oncologic Hospital, Sofia, Bulgaria (1991-2009) are presented. The surgery mode and postoperative treatment was according the stage and histological type of the tumors. These patients were Stage IA, and one patient was Stage IIIC. A follow-up period till 31 December 2012 all the patients are free of disease.
\end{abstract}

Keywords: Endometrial cancer; Very young female

\section{Introduction}

Endometrial cancer is the most common gynecological cancer and is a disease of postmenopausal women. The mean age at diagnosis is 61 years. The disease is rare in young women. It is relatively rare in the young age group (younger than 40 years old) and accounts only for $2.1-14.4 \%$. Only some cases of younger than 30 years old are published [1-5].

Endometrial cancer can be represented as a tumor with two different etiologies. The first one is related with obesity, hypertension and diabetes, and associated with estrogen therapy. The second type of tumor is rare and is not associated with estrogen therapy. Women under 40 who are not obese are at higher risk [6]. Most often this is serious carcinoma or clear-cell carcinoma. Tumors that refer to the second type are worse prognosis and a higher percentage of local recurrence [7,8]. Risk factors for endometrial cancer are: increasing age, long-term exposure to unopposed oestrogens, residence in North America or Europe, high concentrations of oestrogens postmenopausally, metabolic syndrome (obesity, diabetes), years of menstruation, nulliparity, history of breast cancer, long-term use of tamoxifen, HNPCC family syndrome, hormone-replacement therapy with less than 12-14 days of Progestagens, first-degree relative with endometrial cancer [9]. These patients usually present with estrogen or hormone-related disorders such as nulliparity, obesity, and infertility. In general, endometrial carcinoma arising from young patients tends to be well differentiated and have favorable histologic type, infrequent myometrial invasion, and lack of extrauterine spread [10,11]. Women with endometrial carcinoma may be treated successfully with progestin therapy alone as primary therapy to preserve childbearing potential [11]. There is significantly increasing literature available regarding the management of young women with endometrial cancer, including fertility sparing techniques, such as treatment with progestin based therapies. Conservative treatment is indicated for young women stage I, high-differentiated adenocarcinoma who want to keep childbirth potential. The treatment with Medroxyprogesterone acetate is not always a consistent management for every patient [4]. Women under 40 who are not obese are at higher risk of both advanced disease and high-risk histology [5].

\section{Cases Report}

Four case of endometrial cancer in 20 years old or less female, treated at Department of Gynecological Oncology, National Oncologic Hospital, Sofia, Bulgaria (1991-2009) are presented. The choice on conducting conservative treatment or operation is discussed with the patients. If the patients insisted on hysterectomy, the procedure was carried on. The surgery mode and postoperative treatment was according the stage and histological type of the tumors.

\section{Case 1}

On 1991, 20 years old female with menorrhagia of 3 months duration was diagnosed histological as Stage IA grade I endometrial adenoacanthoma with invasion of half of myometrium. Baseline investigations revealed normal. Chest X-ray, electrocardiogram, liver and kidney function were normal. Ultrasound of the abdomen documented normal uterus. Contrast CAT scan of the abdomen and pelvis was normal. Patient underwent hysterectomy with bilateral salpingo-oophorectomy. A Stein-Leventhal syndrome was presented (BMI of 30). Diabetes, hypertension, inheritable syndrome for endometrial cancer or any other risk factors were found. Patient received postoperative adjuvant external beam radiation therapy to a total dose of 52 Gray, and a case was published [12]. On 2008 a Stage I grade I ductal carcinoma of the breast was detected. A sector resection with lymph node dissection was performed. Patient received postoperative adjuvant external beam radiation therapy to a total dose of 50 Gray and hormonal therapy with Zoladex. A follow-up period till 31 December 2012 the patient is free of disease.

\section{Case 2}

On 1999, 20 years old female with menorrhagia of 5 months duration was diagnosed histological as Stage IA grade II endometrial adenocarcinoma with invasion of half of myometrium. $\mathrm{BMI}<25$. Diabetes, hypertension, inheritable syndrome for endometrial cancer or any other risk factors were found. Baseline investigations revealed mild anemia. Chest X-ray, electrocardiogram, liver and kidney function were normal. Ultrasound of the abdomen documented only bulky uterus. Contrast CAT scan of the abdomen and pelvis was normal. Patient

*Corresponding author: Prof. Galina Chakalova, MD, PhD, Head Department of Gynecological Oncology, Nacional Oncological Center, 6 Plovdivsko pole Str, 1715, Sofia, Bulgaria, Tel: 00359888453048; Fax: 0035928765755; E-mail: galiacha@abv.bg

Received February 13, 2013; Accepted March 12, 2013; Published March 14 2013

Citation: Chakalova G (2013) Endometrial Carcinoma in a 20 Years Old or Less Female: A Rare Presentation of Four Cases. J Clin Case Rep 3: 260 doi:10.4172/2165-7920.1000260

Copyright: (c) 2013 Chakalova G. This is an open-access article distributed unde the terms of the Creative Commons Attribution License, which permits unrestricted use, distribution, and reproduction in any medium, provided the original author and source are credited. 
underwent hysterectomy with bilateral salpingo-oophorectomy and bilateral pelvic lymph node dissection. Patient received postoperative adjuvant external beam radiation therapy to a total dose of 52 Gray. A follow-up period till 31 December 2012 the patient is free of disease.

\section{Case 3}

On 2004, 19 years old female with menorrhagia of 6 months duration was diagnosed histological as Stage IA grade I endometrial adenocarcinoma with invasion of less than half of myometrium. $\mathrm{BMI}<25$. Diabetes, hypertension, inheritable syndrome for endometrial cancer or any other risk factors were found. The patient has a child. Baseline investigations revealed mild anemia. Chest $\mathrm{X}$-ray, electrocardiogram, liver functions and kidney function were normal. Ultrasound of the abdomen documented only bulky uterus. Contrast CAT scan of the abdomen and pelvis was normal. Patient underwent hysterectomy with bilateral pelvic lymph node dissection. Ovarian transposition was performed. Patient received postoperative adjuvant external beam radiation therapy to a total dose of 44 Gray and postoperative adjuvant high-dose-rate intravaginal brachytherapy in 8 fractions to $3 \mathrm{~Gy}$. A follow-up period till 31 December 2012 the patient is free of disease.

\section{Case 4}

On 2009, 20 years old female with menorrhagia of 4 months duration was diagnosed histological as Stage IIIC grade I endometrial clear cell carcinoma with invasion of less than half of myometrium and metastasis in 1 lymph node. $\mathrm{BMI}<25$. Diabetes, hypertension, inheritable syndrome for endometrial cancer or any other risk factors were found. Baseline investigations revealed mild anemia. Chest X-ray, electrocardiogram, liver and kidney function were normal. Ultrasound of the abdomen documented only bulky uterus. Contrast CAT scan of the abdomen and pelvis was normal. Patient underwent hysterectomy with bilateral salpingo-oophorectomy and bilateral pelvic lymph node dissection. Patient received postoperative adjuvant external beam radiation therapy to a total dose of 52 Gray and chemotherapy. A follow-up period till 31 December 2012 the patient is free of disease.

\section{Discussion}

Carcinoma of the endometrium is rare below the age of 30 years [3]. The occurrence of the disease at a young age can be related to prolonged unopposed estrogen exposure, and the women usually suffer from hormone-related disorders such as obesity, nulliparity and polycystic ovary syndrome. In $58 \%$ of young patients with endometrial cancer had a BMI of 30 or greater, $55 \%$ were nulliparous and $39 \%$ reported irregular menstrual cycles. The incidence of both diabetes and hypertension was $23 \%$ and $19 \%$ had synchronous ovarian cancers [13]. In our group patient from case 1 had irregular menstrual cycles [12]. The same patient was with multiple primary malignant tumor- breast cancer. These patients are at an increased risk of synchronous tumors of the ovary when compared with the general population. On 2007, 21 year old patient with an apparent early stage endometrial cancer and desiring conservative management was reported. After failure of conservative management for 3 years, surgery was performed. An incidentally small papillary serous ovarian tumor of low malignant potential was found. Careful preoperative and intraoperative assessment of the adnexa is mandatory in young women with endometrial cancer. Those who desire ovarian preservation should be counseled regarding the high potential for coexisting ovarian malignancy [14]. Deciding on conservative treatment, oncologist takes many risks, such as inadequate staging and treatment, risk of synchronous and metahronous tumors, and nonhereditary genetic diseases [15]. It has been observed that the younger patients with cancer of uterus carry a higher risk for the development of ovarian malignancy in the range of 5-29\% [16]. Women with synchronous ovarian and endometrial cancers exhibit favourable survival outcomes as compared with patients with single ovarian cancers, even after adjusting for demographic, prognostic (including stage), and treatment characteristics [17]. Conservative treatment is indicated for young women stage I, high-differentiated adenocarcinoma who want to keep childbirth potential. Treatment consists in the application of medroxyprogesterone acetate at a dose of $500 \mathrm{mg}$ daily and levonorgestrel-releasing intrauterine system [18]. Fertility-preserving treatment with medroxyprogestreone acetate (400$600 \mathrm{mg} /$ day) for 6-10 months, with endometrial curettage performed every four weeks is recommended [19]. Fertility-sparing management was highly effective and safe in cases with $\mathrm{BMI}<25 \mathrm{~kg} / \mathrm{m}^{2}$ [20]. There are therapeutic dilemmas regarding conservative management of endometrial cancer in young women. Two of 9 patients developed recurrent disease 10 and 22 months after the last dilatation and curettage, and both had synchronous ovarian cancer. Patients with an initial partial response can obtain complete response after further conservative treatment [21]. In the 12 patients who received hormonal treatment, 8 patients eventually received a hysterectomy because of recurrence or no response to MPA [4]. Women with $\mathrm{BMI}<25$ were more likely to have advanced disease. Of the 4 patients with high-risk histology (clear cell or serous papillary), all had $\mathrm{BMI}<25$. Women under 40 who are not obese are at higher risk of both advanced disease and high-risk histology [5].

In our series one patient was with BMI of 30 and polycystic ovary syndrome. The rest 3 patients were with $\mathrm{BMI}<25$. No case of diabetes, hypertension, inheritable syndrome for endometrial cancer or any other risk factors were found.

In our series four very young female in 20 years old or les are presented with very good results of the treatment. Fertility-preserving treatment is indicated for young women stage I, high-differentiated adenocarcinoma. In our series only one patient was with such a tumor, but she has a child and insisted on hysterectomy, the procedure was carried on with ovarian conservation (case 3). In the rest cases the conservative treatment was contraindicated, because histological type (adenoacanthoma in case 1), grade (grade II in case 2), and stage (Stage IIIC in case 4). Adjuvant radiation therapy was performed according decision of the Cancer Committee. The presence of clear cell in very young women is not typical, but the second type of endometrial cancer is not associated with estrogen therapy and worse prognosis and a higher percentage of local recurrence are reported [6-8].

In our series four women aged 20 or younger are presented, something that is very rare. This is more of a coincidence than to suggest the presence of hereditary factor.

To date, various studies have been published and progestin therapy has been proven effective for well-differentiated endometrial cancer. However, most of the studies were retrospective, the exception being one prospective study [22]. Of the 9 patients, 8 (88.9\%) achieved complete remission after hormone therapy. Four patients had ever conceived (two patients had three term pregnancies and underwent consolidation hysterectomy after completion of family planning). In a multicenter study of 43 patients was conducted five months conservative treatment. In the follow-up period of 49 months in 2 cases subsequently relapsed, and 31 pregnant women from 3 to 18 months after treatment [23]. 
In conclusion, primary treatment with progestin may be an effective and relatively safe choice of treatment for women with welldifferentiated endometrial adenocarcinoma who wish to preserve fertility.

\section{References}

1. Fadhlaoui A, Hassouna JB, Khrouf M, Zhioua F, Chaker A (2010) Endometrial adenocarcinoma in a 27-years old women. Clin Med Insights Case Rep 3: 31 39.

2. Shyamala G, Lavanya R, Prashanth A, Rajagopal K, Kurien NJ, et al. (2008) An unusual case of endometrial cancer in a young lady. Int J Oncol 5: 1.

3. Gupta M, Malik TR, Wani ML, Lone MM (2012) Endomerial carcinoma in a 20 years old female: a rare presentation. J Clin Case Rep 2: 9.

4. Ota T, Yoshida M, Kimura M, Kinoshita K (2005) Clinicopathologic study of uterine endometrial carcinoma in young women aged 40 years and younger. Int J Gynecol Cancer 15: 657-662.

5. Duska LR, Garrett A, Rueda B R, Haas J, Chang Y, et al. (2001) Endometria cancer in women 40 years old or younger. Gynecol Oncol 83: 388-393.

6. Bokhman JV (1983) Two pathogenetic types of endometrial carcinoma Gynecol Oncol 15: 10-17.

7. Silverberg SC, Kurman RJ, Nogales F, Mutter GL, Kubik-Huch RA, et al (2003) Epithelial tumors and related lesions. In: World Health Organization Classification of tumors. Pathology and genetics of tumors of the breast and female genital organs. IARC Press 221-232.

8. Ronnett BM, Zaino RJ, Hedric ELH, Kurman RJ (2002) Endometrial carcinoma. In: Blauestein,s Pathology of the female genital tract. $5^{\text {th }}$ Edition, Eds. Kurman E.J. New York. Springer-Verlag 501-559.

9. Amant F, Moerman P, Neven P, Timmerman D, Van Limbergen E, et al. (2005) Endometrial cancer. Lancet 366: 491-505.

10. Crissman JD, Azoury RS, Barnes AE, Schellhas HF (1981) Endometria carcinoma in women 40 years of age or younger. Obstet Gynecol 57: 699-704.

11. Kim YB, Holschneider CH, Ghosh K, Nieberg RK, Montz FJ (1997) Progestin alone as primary treatment of endometrial carcinoma in premenopausal women.Report of seven cases and review of literature. Cancer 79: 320-327.

12. Chakalova G, Karag'ozov A (1991) A rare case of endometrial adenoacanthoma in a young woman in combination with the Stein-Leventhal syndrome. Akush Ginekol (Sofia) 30: 66-67.
13. Soliman PT, Oh JC, Schmeler KM, Sun CC, Slomovitz BM, et al. (2005) Risk factors for young premenopausal women with endometrial cancer. Obstet Gynecol 105: 575-580.

14. Shamshirsaz AA, Withiam-Leitch M, Odunsi K, Baker T, Frederick PJ, et al (2007) Young patients with endometrial carcinoma selected for conservative treatment: A need for vigilance for synchronous ovarian carcinomas, case report and literature review. Gynecol Oncol 104: 757-60.

15. Kesterson JP, Fanning J (2012) Fertility-sparing treatment of endometrial cancer: options, outcomes and pitfalls. J Gynecol Oncol 23: 120-124.

16. Walsh C, Holschneider C, Hoang Y, Tieu K, Karlan B, et al. (2005) Coexisting ovarian malignancy in young women with endometrial cancer. Obstet Gyneco 106: 693-699.

17. Williams MG, Bandera EV, Demissie K, Rodríguez-Rodríguez L (2009) Synchronous primary ovarian and endometrial cancers: a population-based assessment of survival. Obstet Gynecol 113: 783-789.

18. Kim MK, Seong SJ, Lee TS, Kim JW, Nam BH, et al. (2012) Treatment with medroxyprogesterone acetate plus levonorgestrel-releasing intrauterine system for early-stage endometrial cancer in young women: single-arm, prospective multicenter study: Korean gynecologic oncology group study (KGOG2009). Jpn $\mathrm{J}$ Clin Oncol 42: 1215-1218.

19. Niwa K, Tagami K, Lian Z, Onogi K, Mori H, et al. (2005) Outcome of fertilitypreserving treatment in young women with endometrial carcinomas. BJOG 112 317-320.

20. Park JY, Kim DY, Kim JH, Kim YM, Kim KR, et al. (2013) Long-term oncologic outcomes after fertility-sparing management using oral progestin for young women with endometrial cancer (KGOG 2002). Eur J Cancer 49: 868-874

21. Yamazawa K, Hirai M, Fujito A, Nishi H, Terauchi F, et al. (2007) Fertilitypreserving treatment with progestin, and pathological criteria to predict responses, in young women with endometrial cancer. Hum Reprod 22: 19531958.

22. Wang CB, Wang CJ, Huang HJ, Hsueh S, Chou HH, et al. (2002) Fertilitypreserving treatment in young patients with endometrial adenocarcinoma. Cancer 94: 2192-2198

23. Dursun P, Erkanli S, Güzel AB, Gultekin M, Tarhan NC, et al. (2012) A Turkish Gynecologic Oncology Group study of fertility-sparing treatment for early-stage endometrial cancer. Int J Gynaecol Obstet 119: 270-273. 